\title{
Alelopatia de extratos de diferentes órgãos de mulungu na germinação de alface
}

\author{
Andreya K Oliveira ${ }^{1}$; Maria de Fatima B Coelho²; Sandra Sely S Maia ${ }^{1}$; Francisco EP Diógenes ${ }^{1}$; \\ Sebastião Medeiros Filho ${ }^{3}$ \\ ${ }^{1}$ UFERSA, C. Postal 137, 59625-900 Mossoró-RN; oliver_andreya@yahoo.com.br; sandrassm2003@yahoo.com.br; esioporto@ \\ yahoo.com.br; ${ }^{2}$ UNILAB-Area de Desenvolvimento Rural, Av. da Abolição 3, Campus da Liberdade, 62790-000 Redenção-CE;

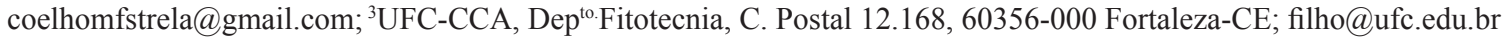

\section{RESUMO}

O mulungu (Erythrina velutina) é uma árvore de crescimento rápido, com propriedades medicinais. $\mathrm{O}$ objetivo no presente trabalho foi avaliar o efeito alelopático do extrato aquoso de sementes, flores e cascas de mulungu na germinação e desenvolvimento de plântulas de alface cv. Mônica SF FI. O delineamento experimental utilizado foi inteiramente casualizado com sete tratamentos [extrato de sementes a $100^{\circ} \mathrm{C}$, extrato de sementes a $25^{\circ} \mathrm{C}$, extrato de cascas a $100^{\circ} \mathrm{C}$, extrato de cascas a $25^{\circ} \mathrm{C}$, extrato de flores a $100^{\circ} \mathrm{C}$, extrato de flores a $25^{\circ} \mathrm{C}$ e água destilada (testemunha)] com quatro repetições. Os extratos obtidos de sementes, independente da temperatura de extração reduziram a porcentagem e velocidade de germinação de sementes de alface e afetaram o desenvolvimento das plântulas. Os demais extratos não afetaram a germinação, mas causaram o aparecimento de plântulas anormais e mortas. Os extratos aquosos de sementes de mulungu têm potencial alelopático sobre as sementes de alface cv. Mônica SF FI.

Palavras-chave: Erythrina velutina, Lactuca sativa, fitotoxidade, plântulas, crescimento.

\begin{abstract}
Allelopathy of extracts of different organs of coral tree on the germination of lettuce

The coral tree (Erythrina velutina) is a fast growing tree with medicinal properties. The aim of this study was to evaluate the allelopathic effects of aqueous extract of seeds, flowers and bark of coral tree on seed germination and seedling development of lettuce cv. Mônica SF FI. The experimental design was completely randomized with seven treatments [seed extract at $100^{\circ} \mathrm{C}$, seed extract at $25^{\circ} \mathrm{C}$, bark extract at $100^{\circ} \mathrm{C}$, bark extract at $25^{\circ} \mathrm{C}$, flower extract at $100^{\circ} \mathrm{C}$, flower extract at $25^{\circ} \mathrm{C}$ and distilled water (control)] with four replications. The extracts of seeds, independent of the extraction temperature decreased the percentage and speed of germination of lettuce and affected the development of the seedlings. The other extracts did not affect germination, but caused the appearance of abnormal seedlings and dead. The aqueous extract of seeds of coral tree has allelopathic potential in the seeds of lettuce cv. Mônica SF FI.
\end{abstract}

Keywords: Erythrina velutina, Lactuca sativa, phytotoxicity, seedling, growth.

\section{(Recebido para publicação em 12 de maio de 2011; aceito em 3 de julho de 2012)} (Received on May 12, 2011; accepted on July 3, 2012)

\begin{abstract}
A palavra alelopatia foi usada pela primeira vez por Hans Molish em 1937 ao descrever as interações químicas positivas e negativas de plantas e microrganismos. A alelopatia refere-se aos efeitos positivos ou negativos de uma planta sobre outra, através da liberação de compostos químicos (aleloquímicos) por lixiviação de partes da planta, exsudados da raiz, volatilização ou decomposição de folhada (Ferreira $\&$ Borghetti, 2004).

Os aleloquímicos podem estar presentes em todos os tecidos das plantas, incluindo folhas, flores, frutos, raízes, rizomas, caules e sementes, mas a quantidade e o caminho pelos quais são liberados diferem de espécie para espécie (Putnan \& Tang, 1986). Por isso, as espécies apresentam diferentes atividades alelopáticas em seus órgãos,
\end{abstract}

como já constataram Gatti et al. (2010) em Aristolochia esperanzae (papo de peru), Souza Filho et al. (2010) em três espécies de Copaifera, e Coelho et al. (2011) em Ziziphus joazeiro (juazeiro).

Os efeitos alelopáticos possuem várias utilizações: contribuir na busca por defensivos agrícolas; compreender o antagonismo de cultivos consorciados ou sucessivos; diminuir o uso de herbicidas sintéticos, substituindo-os por processos de alelopatia; manejar e controlar as ervas daninhas por meio de rotação de cultivos; adequar sistemas de semeadura entre espécies, além de sistemas agroecológicos (Venzon et al., 2005); controlar pragas e plantas invasoras; usar de coberturas mortas ou plantas companheiras e introduzir voluntariamente espécies selvagens (Mallik \& Olofsdotter, 2001).
Erythrina velutina, também conhecida como mulungu, suinã, bico-de-papagaio, canivete, entre outros, pertencente à família Fabaceae (Leguminosae -Papilionoidae), é uma espécie de grande resistência à seca, apresentando rusticidade, rápido crescimento e propriedades medicinais. A planta é decídua, heliófita, característica de várzeas úmidas e beira de rios da caatinga da região semi-árida do Nordeste brasileiro, onde ocorre com elevada frequência e irregular dispersão (Lorenzi, 2009). O gênero é composto aproximadamente de 120 espécies, 70 ocorrendo nas Américas, com apenas uma espécie ocorrendo na caatinga (Queiroz, 2009).

O mulungu é uma árvore com característica ornamental, principalmente quando em flor. Isto tem estimulado seu uso no paisagismo, principalmente na 
arborização de ruas, jardins e alamedas. Possui uma madeira leve, macia e pouco resistente aos agentes decompositores, sendo empregada na confecção de tamancos, jangadas, brinquedos e em caixotaria (Virtuoso, 2005). As propriedades curativas do mulungu foram comprovadas através de estudos farmacológicos, em que o extrato de mulungu mostrou atividades espasmolítica, curarizante, antimuscarínica e depressora do sistema nervoso central, propriedades compatíveis com as preconizadas pelo uso popular (Reyes, 2008).

Outros usos têm se destacado para a espécie. Macedo (2010) isolou uma vicilina de sementes de mulungú que poderia ser indicada como um bioinseticida para ser utilizado nos sistemas integrados de combate a insetos adultos de moscas-das-frutas, com a vantagem de ser biodegradável e atóxico para humanos e animais. Centenaro et al. (2009) verificaram que o extrato etanólico de cascas de mulungu em ensaio alelopático foram capazes de influenciar a germinação e crescimento das plantas de alface.

Nesta perspectiva, este trabalho teve como objetivo verificar atividade alelopática de extratos brutos de sementes, cascas e flores de mulungu na germinação de sementes de alface.

\section{MATERIAL E MÉTODOS}

Os experimentos foram conduzidos no laboratório da UFERSA, em Mossoró (RN), de outubro a novembro de 2009.

Foram utilizadas cascas, flores e sementes de mulungu, coletadas no campus da UFERSA. Sementes de alface da cultivar Mônica SF FI, com percentual de germinação acima de $90 \%$, adquiridas comercialmente na cidade de Mossoró foram utilizadas como espécie teste.

As sementes de mulungu foram coletadas em setembro de 2008 e acondicionadas em câmara fria $\left(18^{\circ} \mathrm{C}\right)$ até a obtenção dos extratos. As flores e as cascas de mulungu foram coletadas às 6 h30 min do dia quatro de setembro de 2009. Foram utilizadas duas porções de 50 g de cada órgão da planta (sementes, flores e cascas), submetidos à lavagem em solução de hipoclorito de sódio (500 mL de água destilada para $10 \mathrm{~mL}$ de hipoclorito de sódio puro) durante cinco minutos.

Depois da assepsia, cada material passou por um processo de secagem em papel toalha. As duas porções de 50 $\mathrm{g}$ de cada órgão foram acondicionadas separadamente em seis beckers. Cada parte da planta recebeu um tratamento quente $(500 \mathrm{~mL}$ de água destilada em ebulição) e um frio (500 mL de água destilada à temperatura ambiente). $\mathrm{O}$ período de extração dos materiais foi de $30 \mathrm{~min}$. Decorrido este período, cada conteúdo foi submetido à trituração em liquidificador domestico por um minuto. Em seguida, o extrato foi submetido à filtragem em pano tipo perfex ${ }^{\circledR}$, onde ficou retido todo o material fibroso.

O material filtrado correspondente a cada extrato foi colocado em recipientes plásticos e submetido a determinações físico-químicas. A determinação do $\mathrm{pH}$ foi feita com um pHmetro e a condutividade elétrica (CE) foi medida pelo condutivímetro. A partir dos valores da CE determinou-se o potencial osmótico (PO) de acordo com a fórmula proposta por Ayers \& Westcot (1999): Potencial osmotico em atmosfera $($ ATM $)=-0,36 *$ CE. Os dados em ATM foram transformados para (Mpa).

$\mathrm{O}$ delineamento experimental foi inteiramente casualizado com sete tratamentos: extrato de sementes a $100^{\circ} \mathrm{C}$ $\left(\right.$ ES $\left.100^{\circ} \mathrm{C}\right)$, extrato de sementes a $25^{\circ} \mathrm{C}$ $\left(\right.$ ES $25^{\circ} \mathrm{C}$ ), extrato de cascas a $100^{\circ} \mathrm{C}$ $\left(\right.$ EC $100^{\circ} \mathrm{C}$ ), extrato de cascas a $25^{\circ} \mathrm{C}$ $\left(\mathrm{EC} 25^{\circ} \mathrm{C}\right.$ ), extrato de flores a $100^{\circ} \mathrm{C}$ $\left(\right.$ EFL $\left.100^{\circ} \mathrm{C}\right)$, extrato de flores a $25^{\circ} \mathrm{C}$ $\left(\mathrm{EFL} 25^{\circ} \mathrm{C}\right.$ ) e água destilada (testemunha) quatro repetições com 20 sementes de alface. Em cada parcela experimental (caixa tipo gerbox) foi colocado com auxilio de uma seringa 8 a $10 \mathrm{~mL}$ do extrato bruto sobre uma folha de papel filtro, previamente esterilizada em estufa a $105 \pm 3^{\circ} \mathrm{C}$ e em seguida as sementes foram distribuídas uniformemente sobre o papel filtro. As caixas gerbox devidamente esterilizadas foram acondicionadas em câmera tipo BOD com temperatura de $25^{\circ} \mathrm{C}$ e fotoperíodo de $12 \mathrm{~h}$, durante sete dias.

O critério para avaliar a germinabi- lidade das sementes baseou-se no conceito de germinação fisiológica citada por Marcos Filho (2005), que aponta o inicio da germinação com a embebição da semente e seu final com a protusão da radícula. A contagem de sementes germinadas foi realizada a cada doze horas durante sete dias A avaliação das plântulas ocorreu no sétimo dia após a semeadura, classificando-as em normais ou anormais, segundo critérios descritos em Brasil (2009). A medição da parte aérea (distância em $\mathrm{mm}$ do colo até o ápice) e da raiz (distância em $\mathrm{mm}$ do colo até o ápice meristemático) de todas as plântulas normais foi feita com auxílio de um paquímetro digital devidamente regulado em $\mathrm{mm}$.

O Índice de Velocidade de Germinação (IVG) foi calculado de acordo com Maguire (1962) pela fórmula $I V G=G_{1} /$ $\mathrm{N}_{1}+\mathrm{G}_{2} / \mathrm{N}_{2}+\ldots+\mathrm{G}_{\mathrm{n}} / \mathrm{N}_{\mathrm{n}}$; em que: $\mathrm{G}_{1}, \mathrm{G}_{2}$, $\mathrm{G}_{\mathrm{n}}=$ número de sementes germinadas computadas na primeira, na segunda e na última contagem; e $\mathrm{N}_{1}, \mathrm{~N}_{2}, \mathrm{~N}_{\mathrm{n}}=$ número de dias da semeadura à primeira, segunda e última contagem. Os dados em percentagem foram previamente transformados em raiz da variável $+0,5$ e submetidos à análise de variância. A comparação das médias foi feita pelo teste Scott Knott a 5\% de probabilidade, utilizando o programa estatístico SAEG (Ribeiro Júnior \& Melo 2009).

\section{RESULTADOS E DISCUSSÃO}

A avaliação de pH e potencial osmótico mostrou que os extratos de mulungu se enquadram na faixa considerada ideal para germinação e pode-se considerar que a acidez do extrato e a concentração de solutos não interferiu nos resultados (Tabela 1). Sabe-se que em condições normais o $\mathrm{pH}$ deve estar compreendido entre quatro e sete e o potencial osmótico $(\mathrm{MPa})$, abaixo de -0,2 (Gatti et al., 2004). Os extratos aquosos podem apresentar determinados solutos que podem alterar a propriedade da água, resultando numa pressão osmótica diferente de zero na solução (Villela et al., 1991). Assim, o controle de pH e da concentração dos extratos é fundamental na realização de ensaios alelopáticos, pois podem haver neles substâncias como açúcares, aminoácidos, entre outros, que podem 
Tabela 1. Características físico-químicas dos extratos aquosos de sementes, flores e cascas de mulungu (E. velutina), (extraídos a 25 e $100^{\circ} \mathrm{C}$ ) utilizados nos bioensaios para avaliação do potencial alelopático sobre sementes de alface [physico-chemical properties of aqueous extracts of seeds, flowers and bark of coral tree (E. velutina), (extracted at 25 and $100^{\circ} \mathrm{C}$ ) used in bioassays to evaluate the allelopathic potential of seeds]. Mossoró, UFERSA, 2009.

\begin{tabular}{lcc}
\hline Extratos aquosos & $\mathbf{p H}$ & PO $\left(\mathbf{M P a} * \mathbf{1 0}^{-\mathbf{2}}\right)$ \\
\hline Sementes $\left(100^{\circ} \mathrm{C}\right)$ & 5,9 & $-9,0$ \\
Flores $\left(100^{\circ} \mathrm{C}\right)$ & 5,5 & $-3,3$ \\
Flores $\left(25^{\circ} \mathrm{C}\right)$ & 5,0 & $-3,4$ \\
Cascas $\left(100^{\circ} \mathrm{C}\right)$ & 6,6 & $-3,6$ \\
Cascas $\left(25^{\circ} \mathrm{C}\right)$ & 5,6 & $-3,6$ \\
Testemunha & 7,1 & $-2,0$ \\
\hline
\end{tabular}

$\mathrm{PO}=$ potencial osmótico $(\mathrm{PO}=$ osmotic potential $)$.

Tabela 2. Germinação e crescimento de plântulas de alface em extratos de mulungu ( $E$. velutina) [germination and seedling growth of lettuce in extracts of coral tree (E.velutina)]. Mossoró, UFERSA, 2009.

\begin{tabular}{|c|c|c|c|c|c|c|}
\hline \multirow{2}{*}{ Extratos aquosos } & PG & PN & PA & IVG * $10^{-1}$ & $\mathbf{C A}$ & CR \\
\hline & \multicolumn{3}{|c|}{$(\%)$} & \multicolumn{3}{|c|}{$(\mathrm{mm})$} \\
\hline sementes a $100^{\circ} \mathrm{C}$ & $6,7 \mathrm{~b}$ & - & $12,0 \mathrm{~b}$ & $0,3 \mathrm{c}$ & - & - \\
\hline sementes a $25^{\circ} \mathrm{C}$ & $13,0 \mathrm{~b}$ & - & $1,0 \mathrm{c}$ & $0,9 \mathrm{c}$ & - & - \\
\hline flores a $100^{\circ} \mathrm{C}$ & $100,0 \mathrm{a}$ & $99,0 \mathrm{a}$ & $0,0 \mathrm{c}$ & $10,8 \mathrm{~b}$ & $19,3 \mathrm{a}$ & $27,90 \mathrm{a}$ \\
\hline flores a $25^{\circ} \mathrm{C}$ & $100,0 \mathrm{a}$ & $77,0 \mathrm{~b}$ & $22,0 \mathrm{~b}$ & $9,5 \mathrm{~b}$ & $16,9 \mathrm{~b}$ & $21,60 \mathrm{~b}$ \\
\hline cascas a $100^{\circ} \mathrm{C}$ & 96,0 a & $63,0 \mathrm{~b}$ & $25,0 \mathrm{~b}$ & $9,7 \mathrm{~b}$ & $13,9 \mathrm{c}$ & $17,00 \mathrm{c}$ \\
\hline cascas a $25^{\circ} \mathrm{C}$ & $93,0 \mathrm{a}$ & $46,0 \mathrm{c}$ & $49,0 \mathrm{a}$ & $11,7 \mathrm{~b}$ & $12,6 \mathrm{c}$ & $20,58 \mathrm{~b}$ \\
\hline testemunha & $100,0 \mathrm{a}$ & $98,0 \mathrm{a}$ & $2,0 \mathrm{c}$ & $14,8 \mathrm{a}$ & $21,2 \mathrm{a}$ & $42,40 \mathrm{a}$ \\
\hline $\mathrm{CV}(\%)$ & 13,5 & 12,5 & 14,9 & 16,5 & 15,6 & 16,7 \\
\hline
\end{tabular}

$\mathrm{PG}=$ porcentagem de germinação; $\mathrm{PN}=$ porcentagem de plântulas normais; $\mathrm{PA}=$ porcentagem de plântulas anormais; $\mathrm{IVG}=$ índice de velocidade de germinação; $\mathrm{CA}=$ comprimento da parte aérea; $\mathrm{CR}=$ comprimento da $\operatorname{raiz}(\mathrm{PG}=$ percentage of germination; $\mathrm{PN}=$ percentage of normal seedlings $\mathrm{PA}=$ percentage of abnormal seedlings; $\mathrm{IVG}=$ germination speed index; $\mathrm{CA}=$ length of shoots, $\mathrm{CR}=$ root length); Médias seguidas da mesma letra, nas colunas, não diferem entre si pelo teste Scott Knott ao nível de 5\% de significância (means followed by same letter in columns do not differ by the Scott Knott test at $5 \%$ significance level).

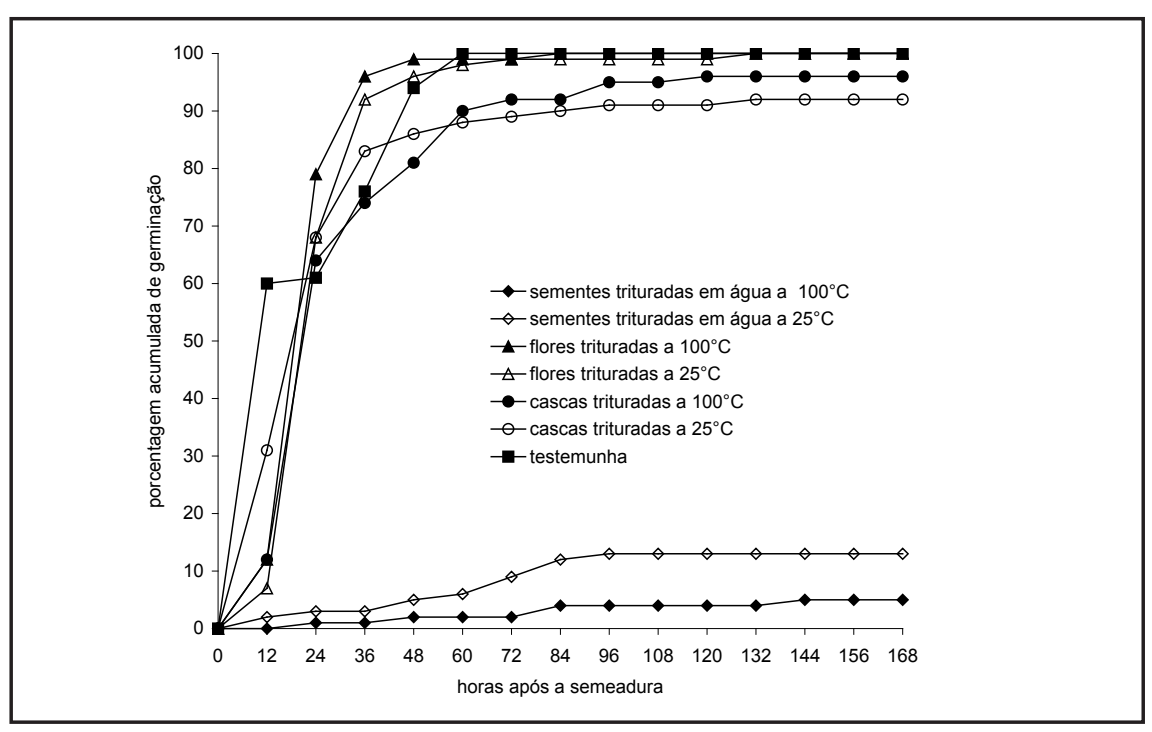

Figura 1. Porcentagem de germinação acumulada de alface em extratos de mulungu ( $E$. velutina) [cumulative germination percentage of lettuce in extracts of coral tree (E. velutina)]. Mossoró, UFERSA, 2009. influenciar na concentração iônica e ser osmoticamente ativos (Ferreira \& Borghetti, 2004) e podem mascarar o fenômeno alelopático (Ferreira \& Aquila, 2000).

Os extratos obtidos de sementes de mulungu, independentes da temperatura de extração, reduziram a porcentagem e velocidade de germinação de sementes de alface cv. Mônica SF FI e também causaram alta porcentagem de mortalidade das sementes (Tabela 2). Coelho et al., (2011) verificaram que o extrato de sementes de juazeiro a $25^{\circ} \mathrm{C}$ reduziu a porcentagem de germinação de sementes de alface para $13 \%$, da mesma forma que o extrato de sementes de mulungu a $25^{\circ} \mathrm{C}$ do presente estudo $(13 \%)$. É possível que a elevada toxidade do extrato de sementes de mulungu deva-se à presença de compostos alopáticos nas sementes, tais como os alcalóides erisopina, erisodina, eritramina e eritracina que estão presentes na planta (Castro, 2006).

Comprovando esse efeito do extrato de sementes observou-se ainda o alto índice de plantas deformadas, com raízes necrosadas e inversão do gravitropismo e alto percentual de plântulas mortas e nenhuma normal (Tabela 2). Anormalidades em plântulas de alface também foram observadas por Gatti et al. (2004) com extratos aquosos de diferentes partes de papo de perú e por Coelho et al. (2011) com extratos aquosos de sementes de juazeiro. A presença de anormalidade em raízes parece ser um bom parâmetro para registro de anormalidade de plântulas, pois este órgão é mais sensível à ação alelopática que a parte aérea (Pires \& Oliveira, 2001).

Muitas vezes, o efeito alelopático não se dá pela germinabilidade, mas sobre a velocidade de germinação ou sobre outro parâmetro do processo (Ferreira \& Borghetti, 2004). Assim, os extratos de flores e de cascas não apresentaram efeitos na porcentagem de germinação, mas causaram redução da velocidade de germinação em relação à testemunha (Tabela 2). $\mathrm{O}$ extrato de cascas a frio $\left(25^{\circ} \mathrm{C}\right)$ provocou o aparecimento de $49 \%$ de plântulas anormais e o extrato de flores $22 \%$ de plântulas com anormalidade. Os extratos de cascas proporcionaram os menores valores do 
comprimento da parte aérea e raiz, comparado à testemunha. Diferenças nas respostas alelopáticas de compostos de diferentes órgãos de uma mesma planta também foram registradas por Aires et al. (2005) em Solanum lycocarpum, por Gatti et al. (2010) em papo de perú e Souza Filho et al. (2010) em três espécies de Copaifera.

Os efeitos alelopáticos podem ser observados tanto sobre a germinação quanto sobre o crescimento da plântula. Ferreira \& Aquila (2000) apontam que a germinação é menos sensível aos aleloquímicos do que o crescimento da plântula, pois as substâncias alelopáticas podem induzir o aparecimento de plântulas anormais, sendo a necrose da radícula um dos sintomas mais comuns. Hagemann et al. (2010) verificaram que o uso de extratos da parte aérea de Avena sativa e Avena strigosa provoca redução na germinabilidade e no crescimento da radícula e do hipocótilo de Lolium multiflorum e Euphorbia heterophylla. Efeito mais drástico sobre o crescimento do que a germinação foi também encontrado por Mazzafera (2003) em Syzygium aromaticum e por Carmo et al. (2007) em Ocotea odorifera.

$\mathrm{O}$ efeito dos extratos sobre o comportamento germinativo de sementes de alface cv Mônica SF FI pode ser comprovado nas curvas de germinação (Figura 1). Após $36 \mathrm{~h}$ da semeadura 90\% das sementes submetidas aos extratos de flores de mulungu e da testemunha já haviam germinado, enquanto nos extratos de cascas a germinação foi mais lenta. Por outro lado, os extratos de sementes causaram germinação ainda mais lenta e baixa, como também foi observado por Coelho et al. (2011) em sementes de alface que germinaram em extratos de sementes de juazeiro.

As sementes de mulungu apresentam dormência que pode ser superada com a remoção de partes do tegumento por escarificação (Silva et al., 2007). É possível que ocorram também compostos inibitórios da germinação no tegumento, talvez os mesmos que impediram a germinação de alface neste estudo. Para averiguar isto, devem ser conduzidos estudos com extratos de diversas partes da semente de mulungu e a composição química dos mesmos determinada.

$\mathrm{O}$ extrato de sementes de mulungu reduz a germinação de sementes da alface cv. Mônica SF FI e os extratos de flores e cascas causam germinação lenta e afetam o desenvolvimento de plântulas de alface.

\section{AGRADECIMENTOS}

Ao Conselho Nacional de Desenvolvimento Cientifico e Tecnologico (CNPq) pela concessão de Bolsa de Produtividade à segunda autora.

\section{REFERÊNCIAS}

AIRES SS; FERREIRA AG; BORGHETTI F. 2005. Efeito alelopático de folhas e frutos de Solanum lycocarpum A. St.-Hil. (Solanaceae) na germinação e crescimento de Sesamun indicum L. (Pedaliaceae) em solo sob três temperaturas. Acta Botanica Brasílica 19: 339-344.

AYERS RS; WESTCOT DW. 1999. Water quality for agriculture. Roma: FAO, 97p. (FAO. Irrigation and Drainage Peper, 29).

BRASIL, Ministério da Agricultura e Reforma Agrária. 2009. Regras para análise de sementes, Brasília: SNAD/CLAV, 395p.

CARMO MSF; BORGES EEL; TAKAKI M. 2007. Alelopatia de extratos aquosos de canela-sassafrás (Ocotea odorifera (Vell.) Rohwer). Acta Botanica Brasílica 21: 697705 .

CASTRO DLL. 2006. Aspectos toxicológicos das plantas medicinais utilizadas no Brasil: um enfoque qualitativo no Distrito Federal. Brasilia:UNB - Centro de Excelência em Turismo. 54p (Monografia)

CENTENARO C; CORRÊA LGP; KARAS MJ; VIRTUOSO S; DIAS JEG; MIGUEL OG; MIGUEL MD. 2009. Contribuição ao estudo alelopático de Erythrina velutina Willd, Fabaceae. Revista Brasileira de Farmacognosia 19: 304-308.

COELHO MFB; MAIA SSS; OLIVEIRA AK; DIÓGENES FEP. 2011. Atividade alelopática de extrato de sementes de juazeiro. Horticultura Brasileira 29: 108-111.

FERREIRA AG; AQUILA ME 2000. Alelopatia: uma área emergente da ecofisiologia. Revista Brasileira de Fisiologia Vegetal 12: 175-204.

FERREIRA AG; BORGHETTI F. 2004. Germinação: do básico ao aplicado. Porto Alegre: Ed. Artimed. 323p.

GATTI AB; FERREIRA AG; ARDUIN M; PEREZ SCGA. 2010. Allelopathic effects of aqueous extracts of Artistolochia esperanzae O. Kuntze on development of Sesamum indicum L. seedlings. Acta Botanica Brasilica 24: 454-461.

GATTI AB; PEREZ SCJG; LIMA MIS. 2004. Efeito alelopático de Aristolochia esperanzae O. Kuntze na germinação e no crescimento de Lactuca sativa L. e Raphanus sativus L. Acta
Botanica Brasilica 18: 459-472.

HAGEMANN TR; BENIN G; LEMES C; MARCHESE JA; MARTIN TN; PAGLIOSA ES; BECHE E. 2010. Potencial alelopático de extratos aquosos foliares de aveia sobre azevém e amendoim-bravo. Bragantia 69: 509-518.

LORENZI H. 2009. Árvores brasileiras: manual de identificação e cultivo das plantas arbóreas nativas do Brasil. Nova Odessa: Instituto Plantarum, 384p.

MACEDO CS. 2010. Efeito inseticida de vicilinas isoladas de sementes de Erythrina velutina em condições de semi-campo para moscas das frutas (Ceratitis capitata). Natal: UFRN 75p (Dissertação mestrado)

MAGUIRE JD. 1962. Speed of germination-aid in selection evaluation for seedling emergence and vigor. Crop Science 2: 176-177.

MALLIK M; OLOFSDOTTER AU. 2001. Allelopathy symposium. Agronomy Journal 93: 1-2.

MARCOS FILHO J. 2005. Fisiologia de sementes de plantas cultivadas. Piracicaba: FEALQ, 495p.

MAZZAFERA P. 2003. Efeito alelopático do extrato alcoólico do cravo-da-índia e eugenol. Revista Brasileira de Botânica 26: 231-238.

PIRES NM; OLIVEIRA VR. 2001. Alelopatia. In: OLIVEIRA JUNIOR. RS; CONSTANTIN J. (coords) Plantas daninhas e seu manejo. Guaíba: Agropecuária. p.145-185.

PUTNAN AR; TANG CS. 1986. In: PUTNAN AR; TANG CS. The science of allelopathy. New York: John Wiley \& Sons. p. 1-19.

QUEIROZ LP. 2009. Leguminosas da Caatinga. Feira de Santana: Editora Universitária da UEFS, 443p.

REYES AEL. 2008. Trilhas da ESALQ: árvores úteis: Erythina velutina Wild. Disponível em: $<$ http://www.esalq.usp.br/trilhas/uteis/ ut02. php>. Acessado em 5 janeiro de 2011.

RIBEIRO JÚNIOR JI; MELO ALP 2009. Guia prático para utilização do SAEG. Viçosa: Editora Independente. 287p.

SILVA KB; ALVES EU; BRUNO RLA; GONÇALVES EP; BRAZ MSS; VIANA JS 2007. Quebra de dormência em sementes de Erythrina velutina Willd. Revista Brasileira de Biociências 5: 180-182.

SOUZA FILHO APS; GURGEL ESC; QUEIROZ MSM; SANTOS JUM. 2010. Atividade alelopática de extratos brutos de três espécies de Copaifera (Leguminosae-Caesalpinioideae). Planta daninha 28: 743-751.

VENZON M; PAULA JÚNIOR TJ; PALLINI A. 2005. Controle alternativo de pragas $e$ doenças. Belo Horizonte: EPAMIG. 359p.

VILLELA FA; DONI FILHO L; SEQUEIRA EL. 1991. Tabela de potencial osmótico em função da concentração de polietileno glicol 6000 e da temperatura. Pesquisa Agropecuária Brasileira 26: 1957-1968.

VIRTUOSO S. 2005. Estudo fitoquímico e biológico das cascas de Erythrina velutina Willd. - Fabaceae (Leguminosae - Papilionoideae). Curitiba: Universidade Federal do Paraná. 103p (Dissertação mestrado) 